\title{
Morphological characterization of cultivars collection of Lettuce (Lactuca sativa L.) from Tunisian oasis
}

\author{
Mohamed Loumerem*, Asma Abed Abdelkader and Samir Tlahig \\ Arid Regions Institute (IRA), Route du Jorf, 4119 Médenine, Tunisia
}

\begin{abstract}
Eight cultivars (CV) of lettuce, collected from Chenini oasis in south of tunisia, were analysed using both univriate and multivariete analysis applied to a set of 33 quantitative and qualitative traits. Results of Duncan test $(\alpha=0.05)$ and coefficient of variance analysis reflected significant differences between cultivars for head weight, head diameter, leaf and seed color. The color of leaves ranges from yellow to darck green with different degrees of shininess. Leaf margin are lobed for CV 2, CV 4, CV 7, CV 8 and entiers for the others cultivars. Seed colour varies including white for cultivars (CV 1, CV 2, CV 4, CV 5), black for (CV 6, CV 7, CV 8) and grey for $\mathrm{CV} 3$.

Mean value of head weight was $340.91 \mathrm{~g}$ and difference between cultivars was highly significant. Minimum head weight value was $115 \mathrm{~g}$ for CV 6 cultivar and maximum value was $755 \mathrm{~g}$ for CV 8 cultivar. On the basis of head characteristics, similar cultivars were clustered according to minimal distance analysis. Three cluster were identified. So, there is no doupt that breeding and selection of lettuce had been practiced by oasis farmers since many years and the accurate description of those oasis lettuce germplasm provides basic information useful for breeders.
\end{abstract}

\section{Introduction}

Lettuce (Lactuca sativa L.) belongs to the genus Lactuca and is classified as belonging to the Asterales Order and Asteraceae Family $[1,2]$. As a cool-season crop, lettuce is extensively grown on all the continents, particularly in temperate and subtropical regions. The genus Lactuca L. (Compositae." Lactuceae) is limited to temperate and Mediterranean regions of the northern hemisphere [3]. It is mainly grown for tender leaves which are mostly used for salad preparation. Lettuce used to be one of the most important crop in arid oasis of Tunisia and the area sown this increased in the last decades. Average yields are around $4110 \mathrm{t} / \mathrm{ha}$. Maximum yields reach $4620 \mathrm{t} / \mathrm{ha}$ in 2011 and minimum yields can be reduced to less than $1000 \mathrm{t} / \mathrm{ha}$ due to water stress [4]. The main abiotic stress in oasis include drought at various growth stages and irrigation water's salinity.

To avoid stress, arid regions growers practiced selection of lettuce for many years, as evidenced by the existence of many cultivars. For this reason, lettuce is receiving increasing attention from breeders and agronomists in Tunisia. Actually, the main interests are to collect, maintain, catalogue and evaluate the Tunisian arid germplasm of Lactuca sativa.

The objective of this study was to classify an Oasen collection of lettuce using a multivariate analysis applied to a set of quantitative traits describing the morphological and agronomical characters of the cultivars with the practical purpose to orientate a breeding program.

\section{Materials and methods}

Eight cultivars of lettuce, collected from Chenini oasis (Figure 1) in south of Tunisia ( $33^{\circ} 53$ North Latitude and $10^{\circ} 12$ Longitude) were studied.

Visits to oasis farm were conducted in 2010 to study local cultivars. During this mission, the seed material of local cultivars was collected and field observations were undertaken. Eight accessions of local cultivars were collected. Seed color varies, including white yellow, brown, gray and black (Figure 2).

All cultivars were evaluated ex situ at ASOC's (Association de Sauvegarde de l'Oasis de Chenini) experimental station of Chenini oasis in Gabes. They compared morphologically to a commercial variety "Batavia Great Lakes" used as a control in order to define the intra and interspecific variation.

Cropping practices are limited to surface ploughing to loosen the surface soil and to eliminate weeds. Subsequent levelling and preparation of planting beds were carried out with hand hoes. In general, farmers make rectangular beds of limited size to guarantee good soil leveling so as to promote even distribution of irrigation water. Sowing is always by hand (broadcasting) whereby seeds are subsequently covered with approximately $0.2 \mathrm{~cm}$ of soil.

After sowing, seed beds were trampled by foot, an operation which slightly covers seeds and ensures intimate contact with the soil.

The experimental design used was marked out into three blocks each comprising nine plots which represent the cultivars and commercial variety. Plot size was $1.5 \mathrm{~m} \mathrm{x} 6 \mathrm{~m}$ and separated by 0.3 $\mathrm{m}$ guard rows. Plants were spaced $0.20 \mathrm{~m}$ and $0.25 \mathrm{~m}$ between and within rows in three repetitions.

*Correspondence to: Mohamed Loumerem, Arid Regions Institute (IRA), Route du Jorf, 4119 Médenine, Tunisia, E-mail: Mohamed.loumerem@ira.rnrt.tn

Key words: cultivar, characterization, cluster, Lactuca sativa, oasis

Received: October 21, 2019; Accepted: November 05, 2019; Published: November 08, 2019 

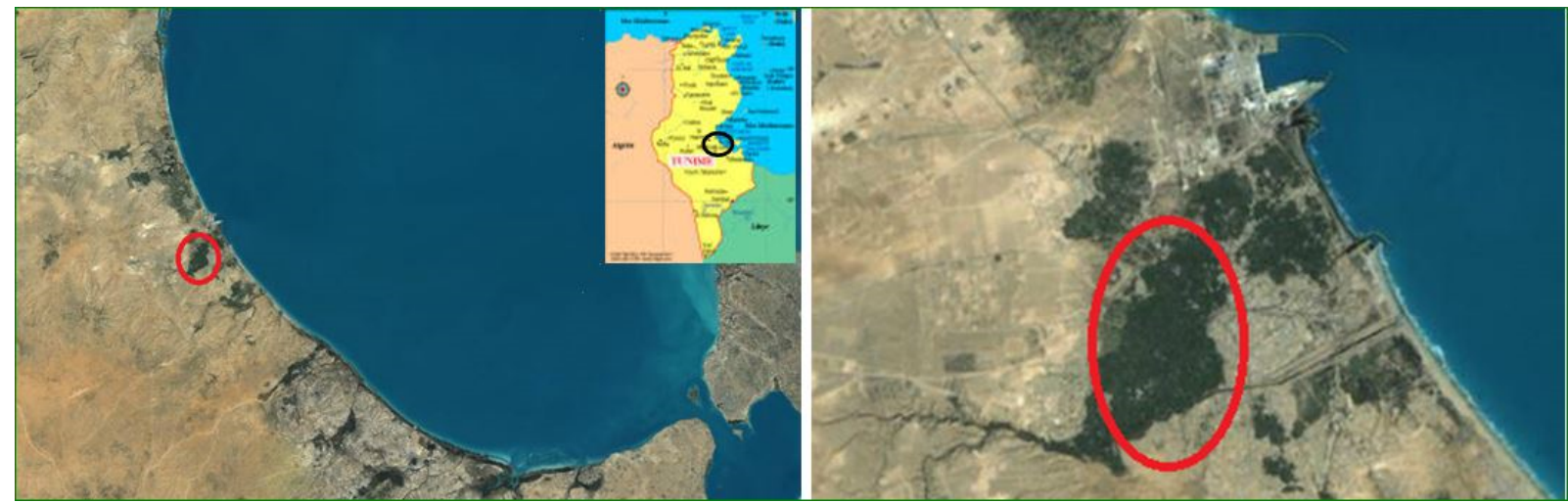

Figure 1. Collection sites of local lettuce cultivars

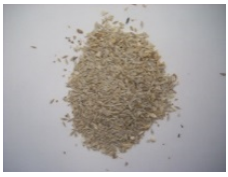

CV1

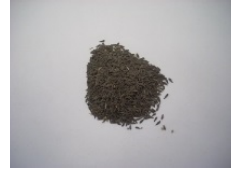

CV 6

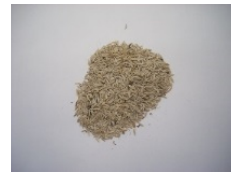

CV 2

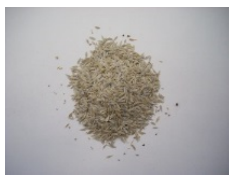

CV 3

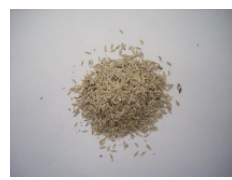

CV 4

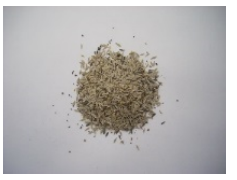

CV 5

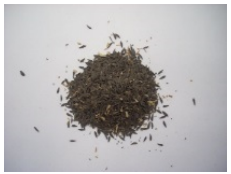

CV 7

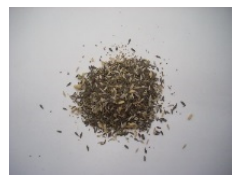

CV8

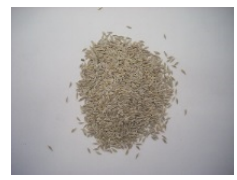

Batavia Great Lakes (control)

Figure 2. Seeds color of studied cultivars

Plants were surface-irrigated at regular 12 to 15 days' intervals. Fertilizers were applied at the rate of $150 \mathrm{~kg}$ nitrogen (applied in three fractions), $50 \mathrm{~kg}$ phosphorus and $50 \mathrm{~kg}$ potassium per ha.

Accessions were scored on different morpho-agronomic characteristics according to the descriptors for lettuce developed by International Union for The Protection of New Varieties of Plants (UPOV, 2006).

Data were analyzed using SPSS software. Analysis of variance (ANOVA, $\alpha=0.05$ ), Duncan test and cluster analysis were applied to all quantitative characters. Hierarchical clustering methods used by many authors for characterization of biodiverse material $[5,6]$, were used to describe genetic variability and in order to group landraces according to different characteristics.

\section{Results and discussion}

Considerable diversity was observed for all characters. Seedling reached tow-leaf stage 40 days after sowing for cultivar 7 , which is the earliest, however cultivars 5 and 6 were the latest. According to Farmers, plant growth rates varies considerably, and the approximate days after emergence for a given leaf stage to appear is influenced most by temperature. Temperature extremes can impose major limitations on crop productivity and production in some areas (Figure 3) [7].

Cultivars 1,2,7,8 and control developed 5 leaves, 75 days after seedling emergence. They are considered the earliest. Lettuce seed fails to germinate at high temperatures. This phenomenon is common in desert region [8].

Quality traits for lettuce (according oasis farms) may be divided into horticultural quality and nutritional quality. Horticultural quality may include production of head weight, head density, heads well filled, firm (not loose) and puffy when squeezed by hand. Leaf is tender and taste. A dark green exterior leaf color is desirable and minimum disease, insect and physical damage.

Results of this preliminary evaluation reflected significant differences among cultivars. Seed color (Figure 1) is white for control, yellow for cultivars $1,2,3,4,5$ and black for cultivars $6,7,8$. Cultivar 8 present mixed seed color yellow and black. The size of cotyledon of seedling (fully developed) is medium for all cultivars and the shape of cotyledon is a broad elliptic for cultivars 3,4,5,6,8 and it is narrow elliptic for the remaining CV. Attitude at 10-12 leaf stage is erect for cultivar1, semi-erect for cultivars $2,3,7,8$ and prostrate for cultivars 4,5 , 6 with leaf blade division is lobed for cultivars $2,4,7,8$ and control. It is entire for the other cultivars.

Most cultivars are closed head (over lopping) and only cultivars 3 and 6 have open heads. The degree of overlopping of upper part of leaves is weak for cultivars $1,4,5,8$. it is medium for cultivars $2,3,6$, control and strong for CV 7.

Head is dense for CV7 and 8, loose for CV3, CV6 and it is medium for the rest of cultivars and control. Head shape of longitudinal section is circular for all cultivars and control.

Leaf taste is bitter for only CV3 and CV5 and leaf thickness is thin for CV6 and medium for all the other cultivars (control included). The leaf shape is circular for CV8 and transverse narrow elliptic for the rest of cultivars however shape of Leaf tip is rounded for all cultivars and control (Figure 4).

The hue of green color of outer leaves is yellowish for all cultivars and control. Leaf blistering is medium for al cultivars expect for CV7 and CV8 have strong leaf blistering with medium size of blisters for cultivars CV7 and CV8 and small for the rest of cultivars. 


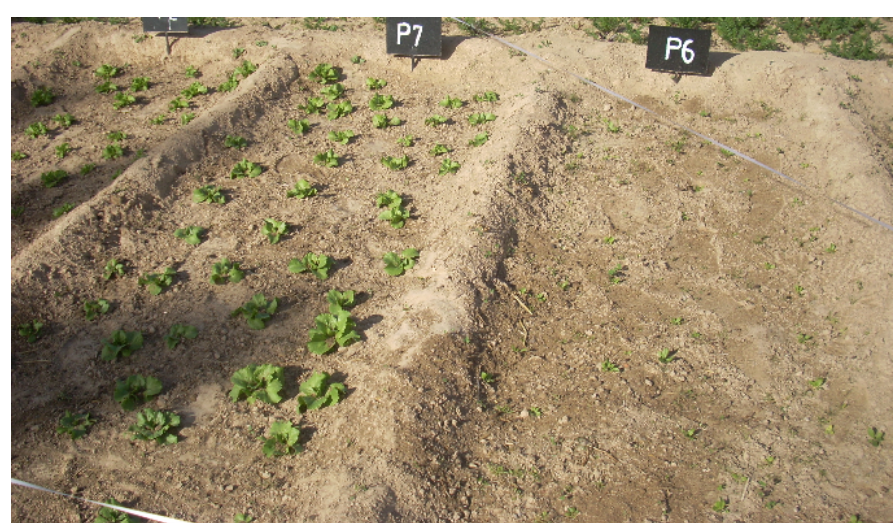

Figure 3. Early emergency of cultivar 7 and lateness of cultivar 6

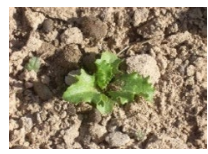

CV1

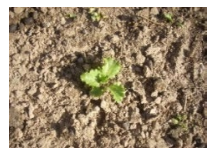

CV 5

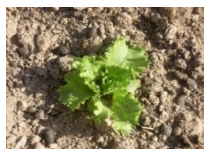

CV 2

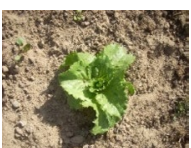

CV 7

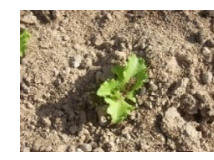

$\mathrm{CV} 3$

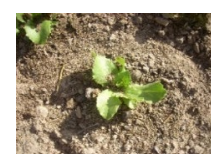

CV 8

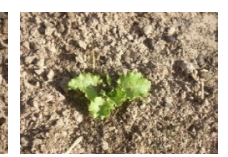

$\mathrm{CV} 4$

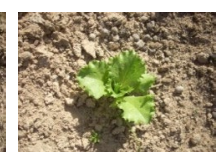

Control
Figure 4. Five-leaf stage (75 days after emergence)

Degree of margin undulation of leaf blade is weak for most cultivars and incision is present in margin on apical part of leaf blade for all cultivars. Leaf blade incisions of apical part are dentate for all cultivars with flabellate venation.

Time of harvest maturity is early for cultivars 7 and 8 . It is late for CV6 and medium for the rest of cultivars. Time of beginning of bolting is early (march) for cultivars 7 and 8. It is late for CV6 (mi-April) and medium for the rest of cultivars and plant fasciation (at flowering stage) is present for all cultivars with medium intensity for some cultivars and weak for the others.

Descriptive statistics of the different quantitative characters (mean value of heads Diameter, Length and Weight for cultivars) are presented in Table 1.

Agronomic evaluation of germplasm accessions revealed considerable diversity among different cultivars for almost all studied characters [9]. Analysis of variance was performed to compare variation between different cultivars.

Head diameter ranges from $5.60 \mathrm{~cm}$ for CV2 to $13.10 \mathrm{~cm}$ for $\mathrm{CV} 8$, with a mean value of $8.85 \pm 1.49 \mathrm{~cm}$. Head Length ranges $6 \mathrm{~cm}$ for CV2 to $13.30 \mathrm{~cm}$ for CV4) with a mean value of $9.30 \pm 1.5 \mathrm{~cm}$. Weight ranges from $115 \mathrm{~g}$ for $\mathrm{CV} 6$ to $755 \mathrm{~g}$ for $\mathrm{CV} 8$ with a mean value of $340.91 \pm 119.59 \mathrm{~g}$ than Height range $18 \mathrm{~cm}$ for CV6 to $105 \mathrm{~cm}$ for CV1 with a mean value of $73.21 \pm 16.77 \mathrm{~cm}$. However, there is no difference between cultivars for the following characters: size of cotyledon of seedling, head shape of longitudinal section, hue of green color of outer leaves, degree of margin undulation of leaf blade, incision is present in margin on apical part of leaf blade, leaf blade incisions of apical part, leaf blade venation and axillary sprouting.

It could be concluded that CV 7 and 8 (Table 1) seemed to be the best in their quality, i.e., compactness, size and average head weight as well as productivity. Differences among oasis lettuce cultivars are certainly due to their different genetic makeup.

Calculated values of $\mathrm{F}$ (Table 2) show that for all characters studied, inter-cultivars differences are highly significant, therefore the cultivars studied here are considered statistically different.

This is in fact logical because on the one hand, cultivars were selected from various areas, which are distinct in environmental and agricultural parameters, whereas on the other hand, we intended to collect the largest diversity possible. Wurr et al. [10-12] reported the differences in lettuce cultivars performances, due to the differences in the agricultural environment.

For certain characters, we notice high $\mathrm{F}$ values. E.g. diameter $(\mathrm{F}=25.110)$, length $(\mathrm{F}=9.955)$, weight $(\mathrm{F}=15.947)$ and height $(\mathrm{F}=3.620)$. These characters differentiate the landraces studied and allowed to regroup them according to agronomical potential.

To estimate similarity between cultivars, we used Duncan's multiple range test which allows to define homogeneous groups of cultivars, by considering the characters for which the values of $\mathrm{F}$ are significant. We notice several types of overlap in the grouping of cultivars for head weight, diameter and length Table 3. For the majority of characters studied here, cultivars 2-3-4-control appears as a group. Cultivars 7 and 8 form another group, were collected from the same farmer.

We applied a hierarchical clustering method using averages of the studied characters in order to group the studied cultivars into more homogeneous classes or clusters. This analysis reduces data size and therefore complexity of their interpretation [13].

The dendrogram resulting from hierarchical classification of 8 cultivars and control (Euclidean distances calculated on the averages of the studied characters) produced three clusters (Figure 5).

Germplasm was grouped into two interesting clusters of different genetic diversity, each cluster carrying lettuce cultivars sharing common properties and being highly similar to one another. This clustering, combined with other data, and provided a useful overall description of the germplasm [14].

Table 1. Statistics descriptive of quantitative characters mean value of heads diameter, length and weight for studied cultivars

\begin{tabular}{|c|c|c|c|}
\hline Accession & Diameter (cm) & Length (cm) & Weight (g) \\
\hline CV1 & 8.79 & 9.39 & 340.00 \\
\hline CV 2 & 8.06 & 8.70 & 311.07 \\
\hline CV 3 & 8.34 & 8.47 & 267.67 \\
\hline CV 4 & 8.19 & 8.75 & 305.92 \\
\hline CV 5 & 8.74 & 9.62 & 294.00 \\
\hline CV 6 & 7.47 & 8.73 & 272.16 \\
\hline CV 7 & 10.80 & 11.03 & 500.00 \\
\hline CV 8 & 10.72 & 10.27 & 458.40 \\
\hline Control & 8.59 & 8.95 & 316.12 \\
\hline Mean & 8.85 & 9.30 & 340.91 \\
\hline Min & 5.60 & 6.00 & 115.00 \\
\hline Max & 13.10 & 13.30 & 755.00 \\
\hline
\end{tabular}

Table 2. Analysis of variance $(\alpha=0.05)$ of quantitative characters

\begin{tabular}{|l|c|c|c|c|c|}
\hline & Sum of Squares & df & Mean Square & F & Sig. \\
\hline Diameter $(\mathrm{cm})$ & 243.896 & 8 & 30.487 & 25.110 & .000 \\
\hline Length $(\mathrm{cm})$ & 138.338 & 8 & 17.292 & 9.955 & .000 \\
\hline Weight $(\mathrm{g})$ & 1266153.763 & 8 & 158269.220 & 15.947 & .000 \\
\hline Height $(\mathrm{cm})$ & 7144.348 & 8 & 893.043 & 3.620 & .001 \\
\hline
\end{tabular}


Table 3. Duncan's multiple range tests (homogeneous groups of cultivars) head diameter (A), head length (B) and head weight (C)

\begin{tabular}{|c|c|c|c|c|c|c|c|c|c|c|c|c|c|c|}
\hline \multirow{2}{*}{$\begin{array}{c}\text { (A) } \\
\text { Cultivars }\end{array}$} & \multicolumn{4}{|c|}{$\begin{array}{l}\text { Homogeneous groups } \\
\qquad(\alpha=0.05)\end{array}$} & \multirow{2}{*}{$\begin{array}{c}\text { (B) } \\
\text { Cultivars } \\
\end{array}$} & \multicolumn{5}{|c|}{$\begin{array}{l}\text { Homogeneous groups } \\
\qquad(\alpha=0.05)\end{array}$} & \multirow{2}{*}{$\begin{array}{c}\text { (C) } \\
\text { Cultivars }\end{array}$} & \multicolumn{3}{|c|}{$\begin{array}{l}\text { Homogeneous groups } \\
\qquad(\alpha=0.05)\end{array}$} \\
\hline & 1 & 2 & 3 & 4 & & 1 & 2 & 3 & 4 & 5 & & 1 & 2 & 3 \\
\hline 6 & 7.47 & & & & 3 & 8.47 & & & & & 3 & 267.67 & & \\
\hline 2 & 8.06 & 8.06 & & & 2 & 8.70 & 8.70 & & & & 5 & 294.00 & 294.00 & \\
\hline 4 & & 8.19 & 8.19 & & 6 & 8.73 & 8.73 & & & & 6 & 302.22 & 302.22 & \\
\hline 3 & & 8.34 & 8.34 & & 4 & 8.75 & 8.75 & & & & 4 & 305.92 & 305.92 & \\
\hline Control & & 8.59 & 8.59 & & Control & 8.95 & 8.95 & 8.95 & & & 2 & 311.07 & 311.07 & \\
\hline 5 & & 8.74 & 8.74 & & 1 & & 9.39 & 9.39 & & & Control & 316.12 & 316.12 & \\
\hline 1 & & & 8.79 & & 5 & & & 9.62 & 9.62 & & 1 & & 340.00 & \\
\hline 8 & & & & 10.72 & 8 & & & & 10.27 & & 8 & & & 458.40 \\
\hline 7 & & & & 10.80 & 7 & & & & & 11.03 & 7 & & & 500.00 \\
\hline Sig. & .061 & .051 & .088 & .794 & Sig. & .258 & .100 & .089 & .084 & 1.000 & Sig. & .126 & .147 & .131 \\
\hline
\end{tabular}

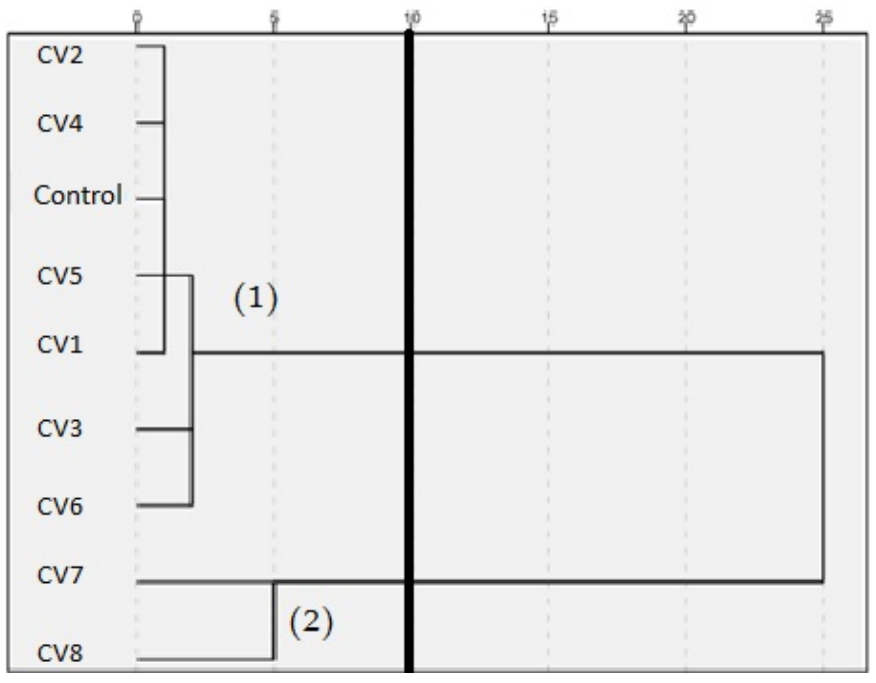

Figure 5. Clusters resulting from the hierarchical classification of 8 cultivars and contro (Euclidean Distances on the averages of the characters, application of Ward's linkage method)

Cultivars in cluster (1) (Figure 5) characteristically had the lowest head weight, head length and head diameter.

Under drought stress condition of oasis, the following cultivars and commercial variety (control) are affected by drought stress (CV1, 2, 3, 4, 5 and CV6).

On the other hand only two accessions (CV7 and CV8) showed good tolerant for salinity and drought in the same time. They are grouped in the second cluster under Oasis conditions.

As expected, the most tolerant cultivars for water salinity were those collected from two experienced farms [15].

Yields are limited more by too little water and high salinity than by any other cause. Yet it is one of the most problems for cropping in oasis environment. Interactions of cultivars and drought have been reported. However, cultivars (7 and 8) showed relatively better performances under dry conditions of oasis.

From small number of these oasis cultivars, which appeared to be not genetically pure, some new cultivars could be obtained which were clearly better than commercial variety "control" subsequently, by breeding new cultivars with adaptation to drought and salinity water could be appreciably improved [16].

\section{Conclusion}

The current work was successful in identifying and collecting promising lettuce germplasm from Oasis regions of Tunisia. This germplasm can be used as a starting basis for a breeding program to select high yielding varieties tolerating adverse arid conditions. In summation, eight cultivars of lettuce, cropped in arid oasis, seem to constitute local germplasm of the cultivated lettuce. Agronomic evaluation of this germplasm revealed considerable diversity among different cultivars for almost all characters studied. It could be concluded that $\mathrm{CV} 7$ and 8 seemed to be the best in their quality, i.e., compactness and size and average head weight as well as productivity. Compared to the commercial lettuce variety "Batavia Great Lakes" the cultivars 7 and 8 show a valuable level of resistance to drought and salt water. There is no doubt that grower practiced and seed selection for many years of lettuce in oasis environment responded by creating new cultivars.

Limited water resources available for crop production is becoming an increasingly concerned problem for arid regions. Development of new cultivars with improved adaptation to drought and salinity environment has been put to be an important goal in crop breeding program. From a breeding point of view, the presence of a remarkable diversity within the oasis germplasm collection appears to be of great interest in providing valuable materials for breeding programs aimed at lettuce improvement for oasis and arid environments. Breeding new cultivars to select adequate levels of drought and water salt resistance across oasis environments continues to be an important objective for lettuce improvement programs, and this collected germplasm needed to achieve this goal.

\section{Acknowledgements}

This research was supported in part by the ASOC (Association de Sauvegarde de l'Oasis de Chenini).

\section{References}

1. De Vries IM, Van Raamsdonk LWD (1994) Numerical morphological analysis of Lettuce cultivars and species (Lactuca sect. Lactuca, Asteraceae) P1. Syst Evol 193: 125-141.

2. Valde R (2012) Potentiel évolutif et adaptation des populations de l'agent du mildiou de la laitue, Bremia lactucae, face aux pressions de sélection de la plante hôte, Lactuca sativa.

3. De Vries IM (1997) Origin and domestication of Lactuca sativa L. Genetic Resources and Crop Evolution 44: 165-174.

4. CRDA (2011) Commissariat Régional pour le Développement de l'Agriculture Gabès. 
5. Peeters JP, Martinelli JA (1989) Hierarchical clustering analysis as a tool to manage variation in germplasm collection. Theor Appl Genet 78: 42-48 .

6. Charmet G, Balfourier F, Bion A (1990) Agronomic evaluation of a collection of French perennial ryegrass populations: Multivariate classification using genotype $\mathrm{x}$ environment interactions. Agronomie 10: 807-823.

7. Jenni S, de Koeyer D, Emery G (2008) Rib discoloration in F2 populations of crisphead lettuce in relation to head maturity. J Amer Soc Hort Sci 133: 249-254.

8. Hurlburt II MW, Ray DT (1996) Thermodormancy in lettuce. University of Arizona and USDA-ARS scientists. Vegetable Report 1996-35: 201-205.

9. Kř́istková E, Doležalová I, Lebeda A, Vinter V, Novotná A (2008) Description of morphological characters of lettuce (Lactuca sativa L.) genetic resources. Hort Sci 35: $113-129$

10. Wurr DCE, Fellows JR (1984) The growth of three crisp lettuce varieties from different sowing dates. J Agric Sci 102: 733-745.

11. Wurr DCE, Fellows JR, Pittam AJ (1987) The influence of plant raising conditions and transplant age on the growth and development of crisp lettuce. J Agric Sci 109: 573-581.
12. Wurr DCE, Fellows JR (1988) Crop continuity and prediction of maturity in the crisp lettuce variety saladin. J Agric Sci 111: 481-486.

13. Fox PN, Crossa J, Romagosa I (1997) Multi-environment testing and genotype $x$ environment interaction. In: Kempton RA, Fox PN (eds) Statistical methods for variety evaluation. CIHEAM, Zaragoza, Spain, pp: 117-138

14. Lebeda A, Jendrulek T (1987) Cluster analysis as a method for evaluation of genetic similarity in specific host- parasite interaction (Lactuca sativa - Bremia lactucae). Theor Appl Genet 75: 194-199.

15. El-sharkwy A (1990) A review of genetic advances on breeding salt-tolerant crops In Dollé V. (ed.), Toutain G. (ed.) Les systèmes agricoles oasiens. Montpellier : CIHEAM-IAMM, 1990: réf., tabl. (Options Méditerranéennes : Série A. Séminaires Méditerranéens; $n^{\circ} 11$ ) Séminaire sur les Systèmes Agricoles Oasiens, 1988/11/19-21, Tozeur (Tunisia) pp : 183-190.

16. Trommetter M (2000) Management of plant genetic resources conservation : collection value and development. Cahiers d'etudes et de recherches francophones/Agricultures $9: 381-389$.

Copyright: (C2019 Loumerem M. This is an open-access article distributed under the terms of the Creative Commons Attribution License, which permits unrestricted use, distribution, and reproduction in any medium, provided the original author and source are credited. 